OPEN ACCESS

Edited by:

Emmanuel Pinteaux

The University of Manchester

United Kingdom

Reviewed by:

Yuchuan Ding,

Wayne State University, United States

Fang $\mathrm{Yu}$,

University of Pittsburgh, United States

Ying Wang,

Capital Medical University, China

*Correspondence:

Hao Wang

13701131933@139.com

Yilong Wang

yilong528@aliyun.com

tThese authors have contributed equally to this work

Specialty section:

This article was submitted to

Stroke,

a section of the journa

Frontiers in Neurology

Received: 02 July 2021

Accepted: 04 January 2022

Published: 03 March 2022

Citation:

Wang Y, Chen W, Zhou J, Wang Y, Wang $H$ and Wang $Y$ (2022) Nitrate

Metabolism and Ischemic

Cerebrovascular Disease: A Narrative

Review. Front. Neurol. 13:735181.

doi: 10.3389/fneur.2022.735181

\title{
Nitrate Metabolism and Ischemic Cerebrovascular Disease: A Narrative Review
}

\author{
Yicong Wang ${ }^{1,2,3+}$, Weiqi Chen ${ }^{1,2,3 \dagger}$, Jian Zhou ${ }^{3,4}$, Yongjun Wang ${ }^{1,2}$, Hao Wang ${ }^{3,5 *}$ and \\ Yilong Wang ${ }^{1,2,3 *}$
}

${ }^{1}$ Department of Neurology, Beijing Tiantan Hospital, Capital Medical University, Beijing, China, ${ }^{2}$ China National Clinical Research Center for Neurological Diseases, Beijing, China, ${ }^{3}$ Laboratory for Oral and General Health Integration and Translation, Beijing, China, ${ }^{4}$ School of Stomatology, Capital Medical University, Beijing, China, ${ }^{5}$ Department of Stomatology, Beijing Tiantan Hospital, Capital Medical University, Beijing, China

Inorganic and organic nitrates are present in vivo and in vitro. Inorganic nitrate is considered a pool of nitric oxide (NO), but it can be converted into nitrite and $\mathrm{NO}$ through various mechanisms. It plays an important role in the regulation of complex physiological and biochemical reactions, such as anti-inflammatory processes and the inhibition of platelet aggregation, which are closely related to the pathology and treatment of cerebrovascular disease. Ischemic cerebrovascular disease is characterized by high incidence, recurrence, and disability rates. Nitrate, nitrite, and NO were recently found to be involved in cerebrovascular disease. In this review, we describe the relationship between cerebrovascular disease and nitrate metabolism to provide a basis for further advances in laboratory and clinical medicine.

Keywords: nitrate, nitrite, nitric oxide synthase, nitric oxide, ischemic cerebrovascular disease

\section{INTRODUCTION}

Organic nitric esters such as nitroglycerin have been used widely in clinical and basic studies on ischemic cardiovascular and cerebrovascular diseases (1). Inorganic nitrate can also be considered a physiological source of nitric oxide (NO) in vivo, following transformation, especially in the vascular system (2). Advances in the field of nitrate research have shown that the physiological function of nitrate intake is not only to increase the production of $\mathrm{NO}$, but also that of nitrate itself, nitrite, and other products (3). The intake or metabolism of nitrate, nitrite, and NO can affect vasodilatory and contractile functions, as well as the occurrence and development of inflammation, which is closely related to the pathogenesis of ischemic stroke and cerebral small vessel disease (CSVD).

Ischemic cerebrovascular disease, with their high disability, fatality, and recurrence rates, are a major burden on society and are a major cause of death and disability worldwide (4-6). Stroke, of which the ischemic variety accounts for the majority of events, has been ranked among the top 10 causes of global disease burden and has risen from fifth place in 1990 to third place in 2019 (7). Studies have shown that nitrate, nitrite, and NO in metabolic pathways are closely related to vascular risk factors and the mechanisms of inflammation and endothelial injury $(8,9)$. In this review, we discuss the involvement of nitrate metabolic pathways in different ischemic cerebrovascular disease to provide a basis for translational research for clinical application. 


\section{NITRATE METABOLISM}

\section{Nitric Oxide Synthase}

Nitric oxide was discovered as a second messenger in vivo by Robert F Furchgott, Murad, and Louis J Ignarro, who won the Nobel Prize. It is formed by the reaction of Larginine with oxygen by endothelial cells, and it mediates vasodilation of vascular smooth muscle through the activation of cyclic guanosine monophosphate (cGMP), which is involved in many physiological processes. In the brain, many subtypes of its synthetic enzyme, NOS, are widely found in neurons, astrocytes, perivascular cells, and brain endothelial cells. $\mathrm{NO}$ and NOS regulate neurovascular coupling (NVC), which not only involves morphological connections but also dynamic functional interactions between active neurons and energy demand and supply in the blood vessels. Endothelial NOS (eNOS), calciumindependent inducible NOS (iNOS), calcium-dependent and constitutively expressed neuronal NOS (nNOS) and red blood cell (RBC) NOS are four types of NOS involved in NVC (10). The intestinal pathogen Vibrio parahaemolyticus converts nitrate from NO produced by host iNOS into nitrite, which acts as a signaling molecule to regulate the expression of inflammatory factors (11). The hyperactivation of nNOS after stroke can cause neurological damage, and accordingly, inhibitors of nNOS are being developed as neuroprotective agents $(12,13)$.

Nitrite can also regulate the production of NO by NOS, inducing vasodilation of oxygen-deficient vessels, cell protection after ischemia-reperfusion (I/R), and gene expression (14). This process is more likely to occur under conditions of ischemia and hypoxia. It can be converted into NO by xanthine oxidoreductase, mitochondrial cytochrome, deoxyhemoglobin, and myoglobin (15). Nitrite can also regulate the production of NO by NOS, thereby inducing hypoxic vasodilation, cell protection after $\mathrm{I} / \mathrm{R}$, and modulation of protein and gene expression. Some studies have shown that under severe hypoxia, nitrite, a substrate of eNOS, can generate NO in in vitro experiments.

\section{Nitrate-Nitrite-NO Metabolism}

The source of inorganic nitrate in humans is mainly food, especially vegetables and water (2). The vegetable-rich human diet provides more nitrate than the NOS enzymes produced in a day $(16,17)$. The nitrate from food is reduced to nitrite and then absorbed by the stomach, intestine, and other organs. Endogenous nitrites include oxidized NO and other nutrients. When bioavailability is $100 \%$, nitrate is mainly absorbed in the proximal small intestine, resulting in a significant increase in plasma nitrate concentration within 5-6h of intake. About 75\% of the circulating nitrate is excreted through urine, and $25 \%$ is actively absorbed by salivary glands and secreted into saliva $(18,19)$ (Figure 1).

\section{Nitrate Transporters and Channels}

Sialin is a polyanion transporter that mediates the $\mathrm{H}^{+}$-dependent transport of sialic acid, aspartate, and glutamate. Sialin has several other important roles, including its function as a nitrate transporter. Sialin is mainly expressed in salivary glands, followed by the liver and brain (20). Therefore, the transport of sialin into cells is the key first step in the nitrate metabolic pathway and plays a role in maintaining physiological functions. This step in the salivary gland also provides an unconventional pathway for the subsequent production of nitrite and NO. In addition, various transporters, such as aquaporin 6 (AQP 6) in the kidney, have been shown to function as nitrate channels in mammals (21). The permeability of chloride channels such as cystic fibrosis transmembrane conductance regulator (CFTR) and CLC-5 for nitrate is greater than that of chloride channels; however, the molecular mechanisms are not very clear $(22,23)$. The transport of nitrate through salivary glands to the other organs is an unconventional mode of nitrite and NO movement, especially under conditions of hypoxia and acidosis.

\section{Biochemical Reactions in Nitrate Metabolism}

The nitrate-nitrite-NO pathway is a recently proposed complementary pathway that may be of great importance in maintaining physiological functions and the production of NO by eNOS under pathophysiological conditions (24). In normal whole blood, in the presence of oxyhemoglobin, nitrite is rapidly oxidized to nitrate, and consequently, plasma nitrate is usually much higher than nitrite. In the oral cavity, symbiotic facultative anaerobes effectively reduce nitrate in saliva from exogenous sources to nitrite through the action of nitrate reductase $(2,25)$. Some of these nitrites may in turn produce nitrates and $\mathrm{NO}$ in the digestive system. The nitrate/nitrite metabolic reactions in vivo are summarized below (26-29):

Nitrite reduction

Bacterial reduction of nitrate

$$
\mathrm{NO}_{3}{ }^{-}+\mathrm{e}^{-}+\mathrm{H}^{+} \rightarrow \mathrm{NO}_{2}{ }^{-}+\mathrm{H}_{2} \mathrm{O}
$$

Deoxyhemoglobin/myoglobin

$$
\mathrm{NO}_{2}^{-}+\mathrm{Fe}^{2+}+\mathrm{H}^{+} \rightarrow \mathrm{NO}+\mathrm{Fe}^{3+}+\mathrm{OH}^{-}
$$

Xanthine oxidoreductase

$$
\mathrm{NO}_{2}^{-}+\mathrm{Mo}^{4+}+\mathrm{H}^{+} \rightarrow \mathrm{NO}+\mathrm{Mo}^{5+}+\mathrm{OH}^{-}
$$

Protons

$$
\begin{array}{r}
\mathrm{NO}_{2}^{-}+\mathrm{H}^{+} \rightarrow \mathrm{HNO}_{2} \\
2 \mathrm{HNO}_{2} \rightarrow \mathrm{N}_{2} \mathrm{O}_{3}+\mathrm{H}_{2} \mathrm{O} \\
\mathrm{HNO}_{2} \leftrightarrow \mathrm{H}^{+}+\mathrm{NO}_{2}^{-}
\end{array}
$$

$$
\mathrm{N}_{2} \mathrm{O}_{3} \leftrightarrow \mathrm{NO}+\mathrm{NO}_{2}
$$

Nitrite formation

Auto-oxidation of NO

$$
4 \mathrm{NO}+\mathrm{O}_{2}+2 \mathrm{H}_{2} \mathrm{O} \rightarrow 4 \mathrm{NO}_{2}^{-}+4 \mathrm{H}^{+}
$$




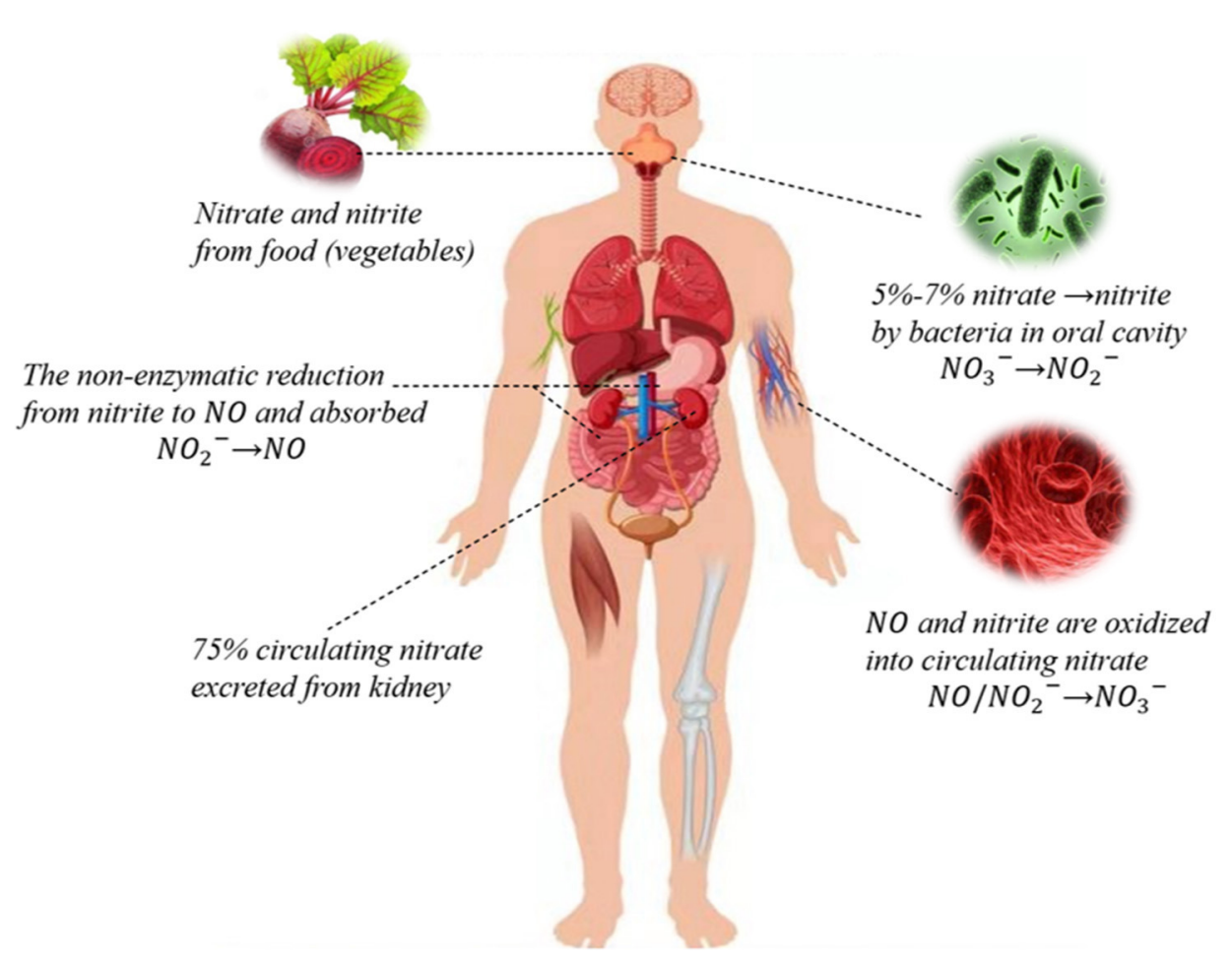

FIGURE 1 | Nitrate-nitrite-NO pathways in humans. Nitrate circulating in the body is mainly derived from the dietary intake of green leafy vegetables, while a small portion of endogenous nitrate is mostly derived from oxidation reactions. Dietary nitrate is converted into nitrite by symbiotic facultative anaerobes in the oral cavity. Nitrite can be reduced to $\mathrm{NO}$ and both can be oxidized to nitrate. About $75 \%$ of circulating nitrate is excreted through urine, and the rest is reabsorbed through the kidneys and bile ducts or absorbed by the salivary gland that is secreted into saliva through sialin or other nonspecific transport channels.

Nitrite oxidation

Hemoglobin

$4 \mathrm{NO}_{2}^{-}+4 \mathrm{HbO}_{2}+4 \mathrm{H}^{+} \rightarrow 4 \mathrm{NO}_{3}^{-}+4 \mathrm{Met}-\mathrm{Hb}+2 \mathrm{H}_{2} \mathrm{O}+\mathrm{O}_{2}$

\section{ROLE OF NITRATE METABOLISM IN ISCHEMIC STROKE RISK}

Common risk factors for stroke include hypertension, dyslipidemia, diabetes, smoking, alcohol, and low fruit and vegetable diet $(30,31)$. The pathways related to nitrate and nitrite metabolism have been shown to be involved in many risk factors in animals and humans.

Some animal experiments have demonstrated that nitrate and nitrite can affect glucose and insulin homeostasis by regulating microvascular blood flow, anti-inflammatory processes, and oxidative stress, especially when endothelial injury and eNOS dysfunction occur $(32,33)$. Inorganic dietary nitrate can also improve the intestinal microbiota and reduce obesity induced by a high-fat diet via its metabolite NO, and ameliorate glucose and lipid metabolic dysfunction in animals (34). Adding nitrate or nitrite to drugs currently used in the treatment of diabetes (such as metformin) and antiobesity drugs can also enhance their efficacy. It has been reported that mice fed a low-nitrate diet exhibit abnormality of visceral fat, dyslipidemia, insulin resistance, and perturbed endothelium-dependent diastolic function compared with mice fed a conventional diet (35). Therefore, improving the physiological function of NO by affecting nitrate-nitrite-NO homeostasis through food intake might reduce risk factors for cerebrovascular disease.

A reduction or an impairment in the utilization of $\mathrm{NO}$ in patients with hypertension affects endothelial function and vasodilation (36). Nitrate and nitrite, as indirect NO sources, have been the focus of an increasing number of studies on blood pressure (24). The downstream effects of nitrate and nitrite include increasing the production of $\mathrm{NO}$ and the modulation of signaling pathways (e.g., cGMP pathways and the activation of $\mathrm{K}^{+}$channels) to promote vasodilation by endothelial cells to significantly reduce blood pressure via smooth muscle relaxation (37). Animal experiments have shown that nitrate can reduce blood pressure in rats with metabolic syndrome or high salt, especially in the preventive application (3840). However, the underlying mechanisms are unclear because numerous pathways likely mediate the hypotensive effects of nitrate. The antihypertensive action of oral nitrite may involve $\mathrm{NO}$ and S-nitroso compounds produced in the stomach. Snitroso compounds formed by nitrite protonation can result in the production of nitrosothiols and nitrosamines. Nitrosothiols 
can react with key protein mercaptans to cause protein Snitrosylation that can strongly impact protein activity. Evidence supporting the antihypertensive action of nitrate and nitrite includes abrogation of their hypotensive effect by proton pump inhibitors (36).

Several clinical trials have shown that nitrate can affect blood pressure. A systematic review of randomized clinical trials of beetroot juice and blood pressure showed that the decrease in blood pressure after taking beetroot juice may help to reduce mortality from cerebrovascular disease, possibly via the nitrate-nitrite-NO pathway. However, the impact of related factors, including baseline blood pressure, overweight/obesity status, gender, and age, is unknown and warrants further investigation. Exogenous nitrate supplementation may regulate blood pressure via numerous mechanisms, and factors that could impact study outcome include gender, age, race, and baseline physical condition. Supplementation should be continued for at least 2 weeks to obtain sustained efficacy $(37,41)$. A metaanalysis confirmed these previous findings, suggesting that beetroot-derived nitrates exert antihypertensive effects, and are a safe and cost-effective nutritional supplement with potential in the management of hypertension and its complications (42). However, in a randomized controlled trial based on more than 200 samples, no blood pressure lowering effect was observed after 5 weeks of dietary inorganic nitrate supplementation. The inconsistency may be related to differences in the source of nitrate in the studies. Nitrate and other compounds in beetroot juice may have an additive effect, or, on the contrary, some compounds in green leafy vegetables may weaken nitrate's action (43). Currently, the evidence from clinical studies is not sufficient, and the conclusions need to be verified.

\section{NITRATE METABOLISM AND ISCHEMIC STROKE}

Ischemic stroke is closely related to the dysfunction of the vascular endothelium, platelet aggregation, and immune inflammation, and microbiotic perturbation. When the $\mathrm{pH}$ in tissue drops sharply because of pathophysiological processes, nonenzymatic reactions in vivo reduce the production of nitrite (27). During tissue hypoxia, the NO production pathway mediated by eNOS is partially inhibited (44). Compared with the traditional L-arginine pathway under aerobic conditions, the NO produced by nitrite in the reduction process is increased 6 -fold (45). In addition, nitrite can also promote the synthesis and release of ATP in erythrocytes under hypoxia and stimulate eNOS to produce NO (46). The pathways involved in nitrate metabolism and stroke are summarized as follows (Figure 2).

\section{Endothelial Dysfunction}

Research on nitrate and endothelium is mostly in the cardiovascular field but is relevant to ischemic cerebrovascular disease. Endothelial dysfunction is a core pathogenetic mechanism in ischemic cerebrovascular disease. During endothelial dysfunction, perturbation of $\mathrm{NO}$ synthesis or superoxide-free radical oxidation of $\mathrm{NO}$ increases the production of toxic substances and leads to increased vascular tension, inflammation, and adhesion of platelets and monocytes to endothelial cells, resulting in atherosclerosis (47). Thus, nitrate/nitrite increases the production of NO when NOS is compromised and exerts antioxidant stress in mitochondria.

Nitric oxide released after ischemia contributes to angiogenesis and vascular remodeling. For example, NO can induce myosin light chain dephosphorylation and increase large conductance calcium-activated potassium channel activation through the cGMP pathway and directly mediate vasodilation (48). NO can also affect the synthesis of prostaglandins and other indirect regulators. The formation of cerebral blood vessels is regulated by adjusting or forming new blood vessels (small artery anastomosis and capillaries) and remodeling small vein blood vessels, thereby enhancing the long-term prognosis of neurological function after stroke (49). Hariharan et al. found that $\mathrm{NO}$ in microvascular tissues was reduced in $\mathrm{eNOS}^{-/-}$ and $\mathrm{NOSS}^{+/-}$mice, as was nitrate. In contrast, COX-2 and thromboxane A2 (TXA 2), the vasoconstrictor and platelet aggregation inducer, were upregulated in $\mathrm{NOS}^{+/-}$mice (50).

Nitrite has been applied for the treatment of I/R injury, and its target is the mitochondria in the heart and liver, where pathophysiological processes occur. In the mitochondrial respiratory chain, complex $I$ is the most sensitive to $I / R$, and is, therefore, a potential target for neuroprotection in stroke. Nitrite inhibits reactive oxygen species (ROSs) overproduction through S-nitrosylation of mitochondrial respiratory chain complex I enzymes after reperfusion (51, 52). Experiments in a rat model of $I / R$ injury showed that nitrite may exert neuroprotection by reducing ROSs production and lipid peroxidation (53). Sodium nitrite may also affect NO production and S-nitrosation and reduce neurological damage after global cerebral ischemia in mice $(53,54)$. However, the pathway through which nitrite mediates NO production during hypoxia remains to be determined but may involve deoxyhemoglobin, deoxymyoglobin, xanthine oxidoreductase, and acid reduction (55). In addition, ischemia increases the release of $\mathrm{Ca}^{2+}$ from the endoplasmic reticulum to the cytoplasm and induces endoplasmic reticulum stress and neuroinflammation. Lowdose sodium nitrite can reduce endoplasmic reticulum stress and decrease the production of ROS, thereby providing tissue protection (56).

In vitro, an $\mathrm{NO}$ donor significantly inhibits the activity of nicotinamide adenine dinucleotide phosphate (NADPH) oxidase by inducing heme oxygenase-1. Nitrate and nitrite supplementation may stimulate the NO signaling pathway, and reduce oxidative stress induced by vascular NADPH oxidase and improve endothelial function. These findings have significance for the nutrition-based prevention and treatment of vascular endothelial dysfunction (57). Current NADPH oxidase inhibitors have various limitations, including low specificity and substantial side effects. If nitrate and nitrite can inhibit NADPH in stroke treatment, it would be a simple, cheap, and relatively safe approach (58). This evidence indicates that inhibition of oxidative stress-related targets by enhancing the nitrate-nitriteNO pathway can reduce inflammation, and may, therefore, have therapeutic potential for endothelial protection (59-62). 


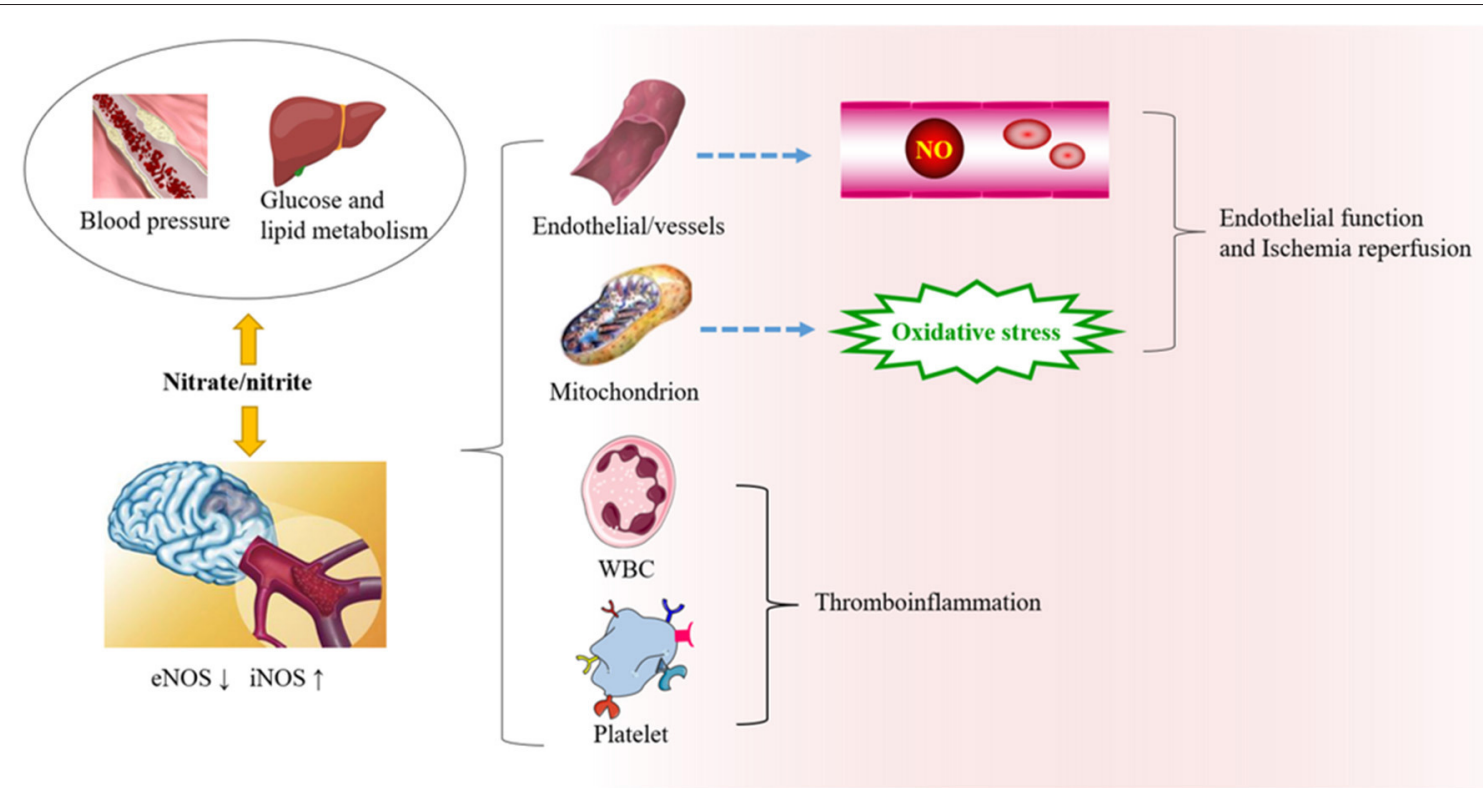

FIGURE 2 | The role of nitrate/nitrite in ischemic cerebrovascular disease. In ischemic cerebrovascular disease, endothelial nitric oxide synthase (eNOS) is downregulated, while iNOS is upregulated. Beneficial NO is thereby reduced, and oxidative stress is increased. Exogenous supplementation of nitrate from food sources has great potential in protecting against oxidative damage, endothelial dysfunction, and thromboinflammation. It can also affect the risk factors related to ischemic cerebrovascular disease, such as blood pressure, blood lipid metabolism, and so on.

Oxidative stress can perturb the endothelium-dependent NO signaling pathway and impair cerebrovascular function. iNOS is also involved in the induction of inflammation after stroke. The iNOS promoter is activated after stroke, and the degree of upregulation is related to the size of the lesion (63). NO from iNOS and superoxide radicals can react to produce peroxynitrite, which can oxidize proteins, lipids, and DNA to cause extensive cell damage (64). The function of $\mathrm{NO}$ or nitrate in ischemic stroke is complex; whether NO is neuroprotective or neurotoxic depends on its source and redox products (65). The role of nitrate may also depend on its concentration, cation type, and exposure time (66). In conclusion, endothelial injury is the core and key step in ischemic cerebrovascular disease. Further, animal experiments and clinical trials are needed to evaluate prevention and treatment strategies (45).

\section{Inflammation and Thrombosis}

Thrombosis is a major result of inflammation and platelet adhesion, activation, and aggregation after endothelial damage. Some small-sample studies have suggested that nitrate can inhibit platelet aggregation in healthy people and patients (67) (Table 1). For example, clinical studies have shown that a proper nitrate diet supplement (from beetroot juice) inhibits platelet aggregation in healthy volunteers. In healthy volunteers, a single supplement of $2 \mathrm{mmol} / \mathrm{L}$ (10.1 mg) of potassium nitrate has been shown to inhibit platelet aggregation (70). A higher nitrate intake through vegetables was related to a decrease in maximum common carotid intima thickness in a cohort study of 1,226 elderly women but was not a predictor of plaque severity. For every 29 $\mathrm{mg} / \mathrm{d}$ increase in nitrate intake from vegetables, the risk of ischemic cerebrovascular disease events decreased by $17 \%$ over 14.5 years (71). In another study, dietary nitrate increased cGMP in platelets in men and improved the responsiveness to $\mathrm{CO}_{2}$ in cerebral vessels of men compared with women, based on a single blind, placebo-controlled crossover trial of 17 patients (74), demonstrating gender-related differences in treatment effects. There are significant differences in oral nitrate metabolism-related microbiota among individuals, and thus, gender differences in microbiota should be examined as an underlying cause $(75,76)$. Nitrate supplementation can also reduce platelet-derived extracellular vesicles and improve the responsiveness of patients to clopidogrel. The effect of adjuvant therapy can also be explored in patients with ischemic cerebrovascular disease because a considerable number of patients with ischemic cerebrovascular disease take clopidogrel (68). In ischemic stroke, extracellular vesicles can promote thrombosis, and an increase in these vesicles is related to the activation of platelets, which is associated with increased risk in young people (77).

Leukocytes infiltrate and promote the destruction of the blood-brain barrier and cause brain parenchymal damage, which is an important contributor to cerebrovascular thrombosis and inflammation after cerebral ischemia (78). Neutrophils are the first cells to migrate from peripheral blood vessels to the ischemic area. In ischemic cerebral vessels, these cells can aggravate the ischemic injury by releasing inflammatory mediators (79). For example, cyclophilin D-mediated platelet necrosis and the ensuing neutrophil recruitment play exacerbate I/R injury after 
TABLE 1 | The effect of nitrate/nitrite on platelet aggregation in humans.

\begin{tabular}{|c|c|c|c|}
\hline Research objects & Treatments & Effects & References \\
\hline $\begin{array}{l}\text { CAD patients with }(n=10) \text { or without } \\
\text { clopidogrel therapy }(n=10)\end{array}$ & $\begin{array}{l}\text { Received a dietary nitrate supplement or } \\
\text { placebo }\end{array}$ & $\begin{array}{l}\text { Nitrate reduced platelet-derived } \\
\text { extracellular vesicles in CAD patients on } \\
\text { clopidogrel therapy, increasing } \\
\text { responsiveness to clopidogrel. }\end{array}$ & $(68)$ \\
\hline Untreated hypercholesterolemics $(n=69)$ & $\begin{array}{l}(250 \mathrm{~mL} \text { ) once-daily intake of dietary } \\
\text { nitrate (beetroot juice) or placebo } \\
\text { nitrate-depleted beetroot juice for } 6 \text { weeks }\end{array}$ & $\begin{array}{l}\text { Dietary nitrate ingestion improved platelet } \\
\text { and vascular function, associated with } \\
\text { alterations in the oral microbiome. }\end{array}$ & (69) \\
\hline Part of the study: healthy volunteers $(n=12)$ & Oral $\mathrm{KNO}_{3}(2 \mathrm{mmol})$ or $\mathrm{KCl}$ & Oral $\mathrm{KNO}_{3}$ inhibited platelet aggregation. & $(70)$ \\
\hline Elderly women $(n=1,226)$ & $\begin{array}{l}<53 \mathrm{mg} / \mathrm{d} \text { vegetable nitrate } \\
53-76 \mathrm{mg} / \mathrm{d} \text { vegetable nitrate } \\
>76 \mathrm{mg} / \mathrm{d} \text { vegetable nitrate, followed up } \\
\text { for } 14.5 \text { years }\end{array}$ & $\begin{array}{l}\text { More nitrate in vegetables can prevent } \\
\text { carotid intima-media thickening and } \\
\text { stroke. }\end{array}$ & $(71)$ \\
\hline Healthy older adults $(n=12)$ & $\begin{array}{l}140 \mathrm{~mL} \text { of beetroot juice (containing } 12.9 \\
\text { mmol nitrate) or nitrate-depleted beetroot } \\
\text { juice }\end{array}$ & $\begin{array}{l}\text { Nitrate supplement reduced the number of } \\
\text { platelet aggregation in monocytes, } \\
\text { indicating that platelet activation was } \\
\text { decreased. }\end{array}$ & $(72)$ \\
\hline Healthy people $(n=24)$ & $\begin{array}{l}\text { Nitrate of } 250 \mathrm{~mL} \text { beetroot juice or } \\
\text { potassium nitrate capsules }\left(\mathrm{KNO}_{3}, 8\right. \\
\mathrm{mmol})\end{array}$ & $\begin{array}{l}\text { The intake of inorganic nitrate reduced } \\
\text { platelet reactivity moderately in healthy } \\
\text { men, but not in women. }\end{array}$ & (73) \\
\hline
\end{tabular}

$C A D$, coronary artery disease.

stroke (80). Neutrophil-derived NO is involved in the production of a large number of free radicals after hypoxia reperfusion (81, 82). Nitrate and nitrite not only cause vasodilation but also affect the function of leukocytes, and may, therefore, have potential in the study of thromboinflammation. Nitrite in drinking water can inhibit the adhesion and migration of leukocytes in mice fed a high-cholesterol diet and reduce inflammatory activation or stabilize atherosclerotic plaques (61). In addition to endothelial cells, iNOS in neutrophils and microglia also mediate tissue damage and further promotes inflammation, which may thus be another potential target of nitrate therapy for thromboinflammation in acute ischemic stroke (83). It is also necessary to study the effects of nitrate and nitrite on antiinflammatory processes and endothelial protection. Reducing oxidative stress might decrease the damage by nitrate and nitrite and their products, and thereby help restore nitrate/NO metabolic homeostasis (84).

\section{Other Mechanisms}

A recent randomized controlled trial showed that nitrate supplementation for 7 days in patients with a transient ischemic episode can reduce blood pressure and cerebral blood flow, and improve cerebral autoregulation, without affecting cerebrovascular $\mathrm{CO}_{2}$ responsiveness (85).

Microbiota is a research hotspot in cerebrovascular disease, especially ischemic cerebrovascular disease. Microbiota may also be related to nitrate metabolism. Nitrate from food, in addition to being transformed into nitrite by microorganisms in the body, has a regulatory effect on human microbiota. Clinical studies show that consuming fruit and vegetable juice containing nitrate for 3 days has a significant effect on the two most abundant phylum of bacteria, Firmicutes and Bacteroidetes, in feces (86). A high ratio of Firmicutes, Bacteroidetes is considered as a sign of intestinal disorder. After an experimental stroke in young mice, the microbial community changes, similar to that in uninjured old mice, in which the ratio of Firmicutes, Bacteroidetes is 9-fold higher than in the young mice (87). NOS2 (iNOS gene) and oxidative stress-related genes are upregulated in acute ischemic stroke. iNOS-derived NO reacts with oxides actively produced by oxidative stress genes to generate nitrate, which destroys the intestinal barrier and causes Escherichia coli to play a proinflammatory role in the anaerobic intestinal environment, thereby aggravating inflammation (88).

\section{NITRATE METABOLISM AND CEREBRAL SMALL VASCULAR DISEASE}

The cerebral small vascular disease mainly affects the cerebral small arteries, small veins, and capillaries (8). CT or MRI shows lacunae, short-term subcortical small infarcts, high intensity of the white matter, enlargement of the perivascular space, microbleeds, and brain atrophy $(89,90)$. At present, the pathophysiological mechanisms of CSVD are not clear but are the focus of the current research. CSVD may be related to chronic ischemia/hypoperfusion, blood-brain barrier damage, and endothelial dysfunction (91-93). CSVD is a relatively unrecognized chronic disease, but its burden is very high, causing between a fifth and a quarter of strokes and nearly half of cognitive impairments (94).

\section{Sporadic Cerebral Small Vessel Disease}

A cross-sectional study showed that arterial stiffness is related to imaging markers of small vessel diseases, including high white matter signal, and cerebral microhemorrhage (95). Arterial stiffness is a pathological factor in vascular diseases, especially of small vessels and microvessels. The most fundamental 
pathological feature in cerebrovascular disease, especially in CSVD, is cerebral atherosclerosis, similar to that in large arteries. NO impacts arterial stiffness by affecting smooth muscle relaxation and vascular tension. The nitrate-nitrite-NO pathway can notably ameliorate arterial pressure in the endothelium and improve arterial stiffness. At present, it is considered that high white matter signals may be related to chronic ischemia and age. Dietary high nitrate does not change overall cerebral perfusion in older adults, but does increase local cerebral perfusion in the frontal white matter, and may play an important role in the improvement of executive and cognitive functions (96).

Inducible nitric oxide synthase, a risk factor for CSVD, can barely be detected in the normal and healthy brain, except in the elderly. Its expression in the elderly is upregulated by cytokines or inflammatory stimulation (64), which may aggravate CSVD via oxidative stress by $\mathrm{NO}$ and nitrate. Intron 4 insertion a/deletion $\mathrm{b}$ genotype of eNOS is associated with simple lacunar infarction. Studies have shown that protection by the $4 \mathrm{a}$ variant might involve modulating eNOS promoter activity and increasing NO levels. The pathological change caused by NO deficiency is local microangioma of proximal arteries rather than diffuse arteriosclerosis of distal arteries (97). The two subtypes of simple symptomatic lacunar infarction and nonischemic white matter hyperintensity may show heterogeneity. There are some studies on the functions of introns $4 \mathrm{a} / \mathrm{b}$ in the eNOS gene and their association with CSVD and its risk factors, but the findings have been inconclusive. Some studies have shown that intron $4 \mathrm{a}$ has a protective effect on cerebral vessels, while others have suggested that its effect may be related to other phenotypic differences. Furthermore, the intronic $4 \mathrm{a}$ allele has been suggested to be a risk factor for lacunar infarction and white matter hyperintensity. These discrepant findings may reflect differences in race and genetic background (97). Therefore, the role of the eNOS gene in different phenotypes of ischemic cerebrovascular disease needs to be further studied and more attention has to be given to whether the sialin gene has a synergistic effect.

\section{Hereditary Cerebral Small Vessel Disease}

In Fabry disease, the X-linked lysosomal storage CSVD disease, the pathogenetic mechanism is endothelial dysfunction (98), where the lack of $\alpha$-galactosidase leads to multiple system defects (99). The level of plasma nitrate in patients with Fabry disease is lower than that in controls, although not statistically significant. The decrease in plasma nitrate may be associated with a change in NO regulation by the endothelium. The metabolic abnormality in this disease may increase $\mathrm{NO}$ and protein nitration in local tissues, and the excessive generation of superoxide is likely to be a contributing pathogenetic factor. The lack of $\alpha$-galactosidase in Fabry disease may account for the excessive production of NO in tissues and the high ROS levels. NO reacts with ROS to form peroxynitrite, which oxidatively reacts with key enzymes and amino acids, leading to cell dysfunction and sometimes death. At the cellular level, NO competes with superoxide dismutase to scavenge ROS. The increase in NO content in tissues may lead to cellular peroxidation by excessive peroxynitrite and nitrotyrosine (100).

\section{NITRATE METABOLISM AND COGNITION}

Vascular dementia is a cognitive impairment caused by cerebrovascular disease (especially ischemic cerebrovascular disease), but there are no licensed treatments for the disorder. The relationship between cerebrovascular pathology and cognitive impairment in vascular dementia is controversial, and the underlying mechanisms need to be further studied (101). Studies have shown a link between nitrogen oxide levels and dementia. The levels of serum nitrogen oxides are significantly lower in patients with dementia, especially in patients with vascular dementia (102).

Nitric oxide synthase and NADPH oxidase may have inflammatory roles in vascular dementia and are important targets in the treatment of vascular dementia (103). Oxidative stress is an important pathogenetic mechanism in vascular dementia and is related to damage to the NOS pathway and endothelial dysfunction (104). Some studies have shown that vascular dementia is an aging-related disease. In one study, nitroglycerin (an NO donor) treatment significantly recovered vasodilatory function in elderly mice. After the application of LNAME (an eNOS inhibitor), the therapeutic effect in young and old mice disappeared, indicating that endothelial dysfunction may also occur in vascular dementia (105). Therefore, nitrate as an inorganic NO donor is worthy of further study in the treatment of vascular dementia.

Anterior cerebral blood flow in patients with vascular dementia is decreased, as shown by imaging studies (106). It was reported that beetroot juice can regulate the cerebral blood flow response to task performance in healthy adults and improve cognitive ability (107). Therefore, the mechanism of vascular dementia may be related to an imbalance in nitrate metabolism, and nitrate supplementation may improve blood flow and brain function, and inhibit inflammatory processes.

\section{SAFETY OF NITRATE AND NITRITE}

With the discovery of the nitrate-nitrite-NO pathway and its physiological significance, inorganic nitrate is now considered a natural NO precursor, and therefore, its beneficial systemic physiological actions deserve attention. The safety of nitrate and nitrite has always been controversial (108). According to the European Food Safety Agency, the average nitrate intake in adults is about $157 \mathrm{mg} /$ day (109). The WHO acceptable daily intake (ADI) for nitrate is $0-3.7 \mathrm{mg} / \mathrm{kg}$, which is equivalent to $222 \mathrm{mg}$ of nitrate in an adult of $60 \mathrm{~kg}$ (110). The so-called carcinogen is actually nitrosamine (111). There is still insufficient evidence that nitrite and nitrate in food can cause cancer (112). Nitrate supplementation from beetroot can also increase the level of $\mathrm{NO}$ metabolites in circulation, increase salivary $\mathrm{pH}$ value, and significantly change oral flora, which is beneficial to oral health, as demonstrated by a single-blind randomized crossover study. This study has significance for the prevention and treatment of periodontitis and caries (113). In fact, with the popularity of a healthy lifestyle and the increase in daily vegetable intake, the reasonable dietary safe dose of inorganic nitrate and its beneficial physiological effects need to be evaluated by higher level animal 
and clinical trials. Thus, while it is considered a safe and good choice to acquire nitrate from food sources, the optimal doses and effectiveness for different diseases need to be investigated.

\section{Prospects}

In cardiovascular and cerebrovascular diseases, endothelial injury is an important etiopathological factor, and a reduction in NO production is a key problem $(2,114)$. The safest and most convenient source of exogenous nitrate is food, especially vegetables. There are also prospects for research on nitrate diet patterns, such as the Mediterranean diet (115). Healthy diet management is an important means of stroke prevention and treatment. Diet habits such as high-salt and high-fat diets are risk factors for stroke. Studies have shown that adhering to the Mediterranean diet can reduce the risk of stroke, although the findings are controversial. In addition, eating more plantbased foods may reduce the risk of stroke recurrence. Vegetables account for a considerable proportion of these healthy dietary patterns, and the benefits of vegetables may include nitrate and NO $(116,117)$.

Drug use in humans is more complicated than in animals. Long-term infusion of large doses of nitrite is needed to effectively reduce vasospasm-related subarachnoid hemorrhage in animal studies, but the dose of nitrite required for protection in the model of I/R injury is very low (29). It is a research objective to provide nitrate and nitrite to experimental animals and evaluate their effect on I/R injury and the protection of multiple organs, and then carry out clinical trials. Small-sample preliminary findings suggest that intravenous nitrite is safe for patients with cardiac arrest. However, a randomized controlled trial involving more than 1,000 patients showed that sodium nitrite treatment did not significantly improve the final hospital survival rate of patients without hospital cardiac arrest (118). In the nitrate metabolic pathway, there is heterogeneity caused by differences in heredity, gender, and age. Therefore, personalizing drugs and their doses for all patient types still requires further study.

The nitrate cycle is affected by many factors. Homeostasis may be affected by dietary habits. If the intake of multiple types of foods and drinks containing polyphenols, which are abundant in red wine, apples, and black tea (119), is increased, a reduction in nitrite can occur in the stomach, thereby reducing blood pressure. However, the effect can be weakened by drugs such as proton pump inhibitors (24). Studies have shown that the intake of sodium nitrite can significantly reduce systolic blood pressure and that esomeprazole pretreatment can eliminate this effect, indicating that the acidic conditions of the gastric cavity are needed for the blood pressure lowering action. The effect of esomeprazole may be related to a reduction in acidity and a decrease in hydrogen ions, which likely affects the nitrate-nitrite-NO pathway $(120,121)$. Being healthy has become a popular concept, particularly the concept of oral health. However, the antibacterial mouthwashes that are commonly used are not necessarily beneficial to whole-body health. While oral antibacterial solutions can kill bacteria in the mouth, they can also decrease the conversion of nitrate to nitrite, and thereby reduce the beneficial effect of exogenous nitrate intake on general health, including the antihypertensive effect $(2,120)$. Therefore, nitrate-reducing bacteria play a significant role in general health by modulating the nitrate-nitrite-NO pathway, and the mechanisms of protection and disease may be a major target of future research (122).

Further studies are required to clarify the link between nitrate/nitrite and cerebrovascular disease. The etiopathogenesis of ischemic stroke and CSVD are very different, but the risk factors are similar to some extent, and both involve microcirculatory disorder, endothelial damage, platelet aggregation, and inflammation. Future studies on nitrate/nitrite and ischemic cerebrovascular disease should identify specific therapeutic targets. Nitrate, nitrite, NO, and their derivatives may play different roles in different stages, and those derived from different sources may influence different pathways. Furthermore, tracing the metabolism of exogenous nitrate supplements and conducting high-level clinical trials should help test and validate current concepts. For the prevention of vascular diseases and their complications, the effects of long-term nitrate supplements need to be investigated by large-scale clinical trials. Currently, there is no safety concern in the intake of these inorganic substances from food at a reasonable dose. Finally, although the nitrate-nitrite-NO pathway is now considered to participate in extremely important physiological processes, research on the nitrate transport-related gene SLC17A5 is still lacking. In addition, while sialin is highly expressed in the brain, it is only known that it primarily transports sialic acid and nitrate and that its loss of function can cause heritable disease, even death. Therefore, it has broad research prospects, such as population genetics and the expression of the SLC17A5 gene, whether different types of ischemic cerebrovascular disease are associated with SLC17A5 and the relationship between sialin and NOS.

\section{CONCLUSION}

There is convincing preliminary evidence for the application of nitrate in both animal experiments and human intervention. Nitrate is particularly important to human physiological and pathophysiological states, and there are potential targets in the vascular system (45). Genes involved in nitrate/nitrite metabolism are related to cerebrovascular disease, and chemical compounds could play an important therapeutic role by providing NO. Nitrate supplementation may be a convenient, economic, and effective way to reduce the risk of ischemic cerebrovascular disease. Furthermore, adjuvant treatment with exogenous supplements or increasing the transformation of nitrate in pathophysiological states may inhibit inflammation and protect the endothelium.

\section{AUTHOR CONTRIBUTIONS}

All authors listed have made a substantial, direct, and intellectual contribution to the work and approved it for publication. 


\section{FUNDING}

This research was supported by grants from the National Natural Science Foundation of China (81825007, 81901177, and 81971091), Beijing Outstanding Young Scientist Program (No. BJJWZYJH01201910025030), National Key R \& D Program of China (Nos. 2017YFC1307900 and 2017YFC1307905), Beijing Hospitals Authority Youth Programme (QML20200501 and QML20190501), Beijing

\section{REFERENCES}

1. Appleton JP, Woodhouse LJ, Sprigg N, Wardlaw JM, Bath PM. Intracranial bleeding after reperfusion therapy in acute ischaemic stroke patients randomized to glyceryl trinitrate vs. control: an individual patient data meta-analysis. Front Neurol. (2020) 11:584038. doi: 10.3389/fneur.2020.5 84038

2. Ma L, Hu L, Feng X, Wang S. Nitrate and nitrite in health and disease. Aging Dis. (2018) 9:938-45. doi: 10.14336/AD.2017.1207

3. Babateen AM, Fornelli G, Donini LM, Mathers JC, Siervo M. Assessment of dietary nitrate intake in humans: a systematic review. Am J Clin Nutr. (2018) 108:878-88. doi: 10.1093/ajcn/nqy108

4. Liu L, Chen W, Zhou H, Duan W, Li S, Huo X, et al. Chinese stroke association guidelines for clinical management of cerebrovascular disorders: executive summary and 2019 update of clinical management of ischaemic cerebrovascular diseases. Stroke Vasc Neurol. (2020) 5:159-76. doi: 10.1136/svn-2020-000378

5. Feigin VL, Vos T, Nichols E, Owolabi MO, Carroll WM, Dichgans M, et al. The global burden of neurological disorders: translating evidence into policy. Lancet Neurol. (2020) 19:255-65. doi: 10.1016/S1474-4422(19)30411-9

6. Pandian JD, Kalkonde Y, Sebastian IA, Felix C, Urimubenshi G, Bosch J. Stroke systems of care in low-income and middle-income countries: challenges and opportunities. Lancet. (2020) 396:1443-51. doi: 10.1016/S0140-6736(20)31374-X

7. Vos T, Lim SS, Abbafati C, Abbas KM, Abbasi M, Abbasifard M, et al. Global burden of 369 diseases and injuries in 204 countries and territories, 19902019: a systematic analysis for the Global Burden of Disease Study 2019. Lancet. (2020) 396:1204-22. doi: 10.1016/S0140-6736(20)30925-9

8. Poggesi A, Pasi M, Pescini F, Pantoni L, Inzitari D. Circulating biologic markers of endothelial dysfunction in cerebral small vessel disease: a review. J Cereb Blood Flow Metab. (2016) 36:72-94. doi: 10.1038/jcbfm.2015.116

9. Zhu J, Song W, Li L, Fan X. Endothelial nitric oxide synthase: a potential therapeutic target for cerebrovascular diseases. Mol Brain. (2016) 9:30. doi: 10.1186/s13041-016-0211-9

10. Tabatabaei SN, Girouard H. Nitric oxide and cerebrovascular regulation. Vitam Horm. (2014) 96:347-85. doi: 10.1016/B978-0-12-800254-4.00014-3

11. Gu D, Zhang Y, Wang Q, Zhou X. S-nitrosylation-mediated activation of a histidine kinase represses the type 3 secretion system and promotes virulence of an enteric pathogen. Nat Commun. (2020) 11:5777. doi: 10.1038/s41467-020-19506-1

12. Hill MD, Goyal M, Menon BK, Nogueira RG, McTaggart RA, Demchuk AM, et al. Efficacy and safety of nerinetide for the treatment of acute ischaemic stroke (ESCAPE-NA1): a multicentre, double-blind, randomised controlled trial. Lancet. (2020) 395:878-87. doi: 10.1016/S0140-6736(20)30258-0

13. Zhou L, Li F, Xu HB, Luo CX, Wu HY, Zhu MM, et al. Treatment of cerebral ischemia by disrupting ischemia-induced interaction of nNOS with PSD-95. Nat Med. (2010) 16:1439-43. doi: 10.1038/nm.2245

14. Tota B, Quintieri AM, Angelone T. The emerging role of nitrite as an endogenous modulator and therapeutic agent of cardiovascular function. Curr Med Chem. (2010) 17:1915-25. doi: 10.2174/092986710791163948

15. Omar SA, Webb AJ, Lundberg JO, Weitzberg E. Therapeutic effects of inorganic nitrate and nitrite in cardiovascular and metabolic diseases. $J$ Intern Med. (2016) 279:315-36. doi: 10.1111/joim.12441
Municipal Science and Technology Commission (Nos. D17110700300000 and D17110000301700), Beijing Tiantan Hospital, Capital Medical University (2018-YQN-1 and 2020MP01), Beijing Excellent Talents Training and SupportingTop Youth Team by Beijing Municipal Science and Technology Commission (No. 2016000021223TD03), Youth Beijing Scholar Program (No. 010), Beijing Talent Project - Class A: Innovation and Development (No. 2018A12), and Young Elite Scientist Sponsorship Program (2019QNRC001).
16. Park JW, Piknova B, Jenkins A, Hellinga D, Parver LM, Schechter AN. Potential roles of nitrate and nitrite in nitric oxide metabolism in the eye. Sci Rep. (2020) 10:13166. doi: 10.1038/s41598-020-69272-9

17. Lundberg JO, Weitzberg E. The biological role of nitrate and nitrite: the times they are a-changin'. Nitric Oxide. (2010) 22:61-3. doi: 10.1016/j.niox.2009.11.004

18. Jackson J, Patterson AJ, MacDonald-Wicks L, McEvoy M. The role of inorganic nitrate and nitrite in CVD. Nutr Res Rev. (2017) 30:247-64. doi: 10.1017/S0954422417000105

19. Xia DS, Deng DJ, Wang SL. Destruction of parotid glands affects nitrate and nitrite metabolism. J Dent Res. (2003) 82:101-5. doi: $10.1177 / 154405910308200205$

20. Qin L, Liu X, Sun Q, Fan Z, Xia D, Ding G, et al. Sialin (SLC17A5) functions as a nitrate transporter in the plasma membrane. Proc Natl Acad Sci U S A. (2012) 109:13434-9. doi: 10.1073/pnas.1116633109

21. Ikeda M, Beitz E, Kozono D, Guggino WB, Agre P, Yasui M. Characterization of aquaporin- 6 as a nitrate channel in mammalian cells. Requirement of pore-lining residue threonine 63. J Biol Chem. (2002) 277:39873-9. doi: 10.1074/jbc.M207008200

22. Anderson MP, Gregory RJ, Thompson S, Souza DW, Paul S, Mulligan RC, et al. Demonstration that CFTR is a chloride channel by alteration of its anion selectivity. Science. (1991) 253:202-5. doi: 10.1126/science.1712984

23. Jentsch TJ, Stein V, Weinreich F, Zdebik AA. Molecular structure and physiological function of chloride channels. Physiol Rev. (2002) 82:503-68. doi: 10.1152/physrev.00029.2001

24. Oliveira-Paula GH, Pinheiro LC, Tanus-Santos JE. Mechanisms impairing blood pressure responses to nitrite and nitrate. Nitric Oxide. (2019) 85:35-43. doi: 10.1016/j.niox.2019.01.015

25. Duncan C, Dougall H, Johnston P, Green S, Brogan R, Leifert C, et al. Chemical generation of nitric oxide in the mouth from the enterosalivary circulation of dietary nitrate. Nat Med. (1995) 1:546-51. doi: $10.1038 / \mathrm{nm} 0695-546$

26. DeMartino AW, Kim-Shapiro DB, Patel RP, Gladwin MT. Nitrite and nitrate chemical biology and signalling. Br J Pharmacol. (2019) 176:228-45. doi: 10.1111/bph.14484

27. Lundberg JO, Weitzberg E. NO generation from nitrite and its role in vascular control. Arterioscler Thromb Vasc Biol. (2005) 25:915-22. doi: 10.1161/01.ATV.0000161048.72004.c2

28. Vanin AF, Bevers LM, Slama-Schwok A, van Faassen EE. Nitric oxide synthase reduces nitrite to NO under anoxia. Cell Mol Life Sci. (2007) 64:96-103. doi: 10.1007/s00018-006-6374-2

29. Lundberg JO, Weitzberg E, Gladwin MT. The nitrate-nitrite-nitric oxide pathway in physiology and therapeutics. Nat Rev Drug Discov. (2008) 7:15667. doi: $10.1038 / \mathrm{nrd} 2466$

30. Wu S, Wu B, Liu M, Chen Z, Wang W, Anderson CS, et al. Stroke in China: advances and challenges in epidemiology, prevention, and management. Lancet Neurol. (2019) 18:394-405. doi: 10.1016/S1474-4422(18)30500-3

31. Zhang P, Jin H, Guo ZN, Sun HJ, Zhang FL, Sun X, et al. The accumulation of key stroke risk factors and its association with the characteristics of subjects: a population based cross sectional study. Front Neurol. (2018) 9:949. doi: 10.3389/fneur.2018.00949

32. Ghasemi A, Jeddi S. Anti-obesity and anti-diabetic effects of nitrate and nitrite. Nitric Oxide. (2017) 70:9-24. doi: 10.1016/j.niox.2017.08.003 
33. Matthews VB, Hollingshead R, Koch H, Croft KD, Ward NC. Longterm dietary nitrate supplementation does not prevent development of the metabolic syndrome in mice fed a high-fat diet. Int J Endocrinol. (2018) 2018:7969750. doi: 10.1155/2018/7969750

34. Ma L, Hu L, Jin L, Wang J, Li X, Wang W, et al. Rebalancing glucolipid metabolism and gut microbiome dysbiosis by nitrate-dependent alleviation of high-fat diet-induced obesity. BMJ Open Diabetes Res Care. (2020) 8:e001255. doi: 10.1136/bmjdrc-2020-001255

35. Kina-Tanada M, Sakanashi M, Tanimoto A, Kaname T, Matsuzaki T, Noguchi K, et al. Long-term dietary nitrite and nitrate deficiency causes the metabolic syndrome, endothelial dysfunction and cardiovascular death in mice. Diabetologia. (2017) 60:1138-51. doi: 10.1007/s00125-017-4259-6

36. Guimaraes DA, Batista RIM, Tanus-Santos JE. Nitrate and nitrite-based therapy to attenuate cardiovascular remodelling in arterial hypertension. Basic Clin Pharmacol Toxicol. (2021) 128:9-17. doi: 10.1111/bcpt.13474

37. Bonilla Ocampo DA, Paipilla AF, Marín E, Vargas-Molina S, Petro JL, Pérez-Idárraga A. Dietary nitrate from beetroot juice for hypertension: a systematic review. Biomolecules. (2018) 8:134. doi: 10.3390/biom80 40134

38. Bhaswant M, Brown L, McAinch AJ, Mathai ML. Beetroot and sodium nitrate ameliorate cardiometabolic changes in diet-induced obese hypertensive rats. Mol Nutr Food Res. (2017) 61:1700478. doi: 10.1002/mnfr.201700478

39. Carlström M, Persson AE, Larsson E, Hezel M, Scheffer PG, Teerlink $\mathrm{T}$, et al. Dietary nitrate attenuates oxidative stress, prevents cardiac and renal injuries, and reduces blood pressure in salt-induced hypertension. Cardiovasc Res. (2011) 89:574-85. doi: 10.1093/cvr/cvq366

40. Essawy SS, Abdel-Sater KA, Elbaz AA. Comparing the effects of inorganic nitrate and allopurinol in renovascular complications of metabolic syndrome in rats: role of nitric oxide and uric acid. Arch Med Sci. (2014) 10:537-45. doi: 10.5114/aoms.2013.33222

41. Ashworth A, Mitchell K, Blackwell JR, Vanhatalo A, Jones AM. High-nitrate vegetable diet increases plasma nitrate and nitrite concentrations and reduces blood pressure in healthy women. Public Health Nutr. (2015) 18:2669-78. doi: 10.1017/S1368980015000038

42. Bahadoran Z, Mirmiran P, Kabir A, Azizi F, Ghasemi A. The nitrateindependent blood pressure-lowering effect of beetroot juice: a systematic review and meta-analysis. Adv Nutr. (2017) 8:830-8. doi: 10.3945/an.117.016717

43. Sundqvist ML, Larsen FJ, Carlström M, Bottai M, Pernow J, Hellénius ML, et al. A randomized clinical trial of the effects of leafy green vegetables and inorganic nitrate on blood pressure. Am J Clin Nutr. (2020) 111:749-56. doi: 10.1093/ajcn/nqaa024

44. Favié LMA, Cox AR, van den Hoogen A, Nijboer CHA, Peeters-Scholte C, van Bel F, et al. Nitric oxide synthase inhibition as a neuroprotective strategy following hypoxic-ischemic encephalopathy: evidence from animal studies. Front Neurol. (2018) 9:258. doi: 10.3389/fneur.2018.00258

45. Hobbs DA, George TW, Lovegrove JA. The effects of dietary nitrate on blood pressure and endothelial function: a review of human intervention studies. Nutr Res Rev. (2013) 26:210-22. doi: 10.1017/S0954422413000188

46. Cao Z, Bell JB, Mohanty JG, Nagababu E, Rifkind JM. Nitrite enhances RBC hypoxic ATP synthesis and the release of ATP into the vasculature: a new mechanism for nitrite-induced vasodilation. Am J Physiol Heart Circ Physiol. (2009) 297:H1494-1503. doi: 10.1152/ajpheart.01233.2008

47. Pesić S, Radenković M, Grbović L. Endothelial dysfunction: mechanisms of development and therapeutic options. Med Pregl. (2006) 59:335-41. doi: 10.2298/MPNS0608335P

48. Dormanns K, Brown RG, David T. The role of nitric oxide in neurovascular coupling. J Theor Biol. (2016) 394:1-17. doi: 10.1016/j.jtbi.2016.01.009

49. Lapi D, Colantuoni A. Remodeling of cerebral microcirculation after ischemia-reperfusion. J Vasc Res. (2015) 52:22-31. doi: 10.1159/000381096

50. Hariharan A, Jing Y, Collie ND, Zhang H, Liu P. Altered neurovascular coupling and brain arginine metabolism in endothelial nitric oxide synthase deficient mice. Nitric Oxide. (2019) 87:60-72. doi: 10.1016/j.niox.2019.03.006

51. Lundberg JO, Carlström M, Weitzberg E. Metabolic effects of dietary nitrate in health and disease. Cell Metab. (2018) 28:9-22. doi: 10.1016/j.cmet.2018.06.007

52. Shiva S, Sack MN, Greer JJ, Duranski M, Ringwood LA, Burwell L, et al. Nitrite augments tolerance to ischemia/reperfusion injury via the modulation of mitochondrial electron transfer. J Exp Med. (2007) 204:2089102. doi: 10.1084/jem.20070198

53. Jung KH, Chu K, Ko SY, Lee ST, Sinn DI, Park DK, et al. Early intravenous infusion of sodium nitrite protects brain against in vivo ischemia-reperfusion injury. Stroke. (2006) 37:2744-50. doi: 10.1161/01.STR.0000245116.40163.1c

54. Fukuda T, Kakinohana M, Takayama C, Matsushita M, Sugahara K. Dietary supplementation with sodium nitrite can exert neuroprotective effects on global cerebral ischemia/reperfusion in mice. J Anesth. (2015) 29:609-17. doi: 10.1007/s00540-014-1968-6

55. Dezfulian C, Raat N, Shiva S, Gladwin MT. Role of the anion nitrite in ischemia-reperfusion cytoprotection and therapeutics. Cardiovasc Res. (2007) 75:327-38. doi: 10.1016/j.cardiores.2007.05.001

56. Shakib N, Khadem Ansari MH, Karimi P, Rasmi Y. Neuroprotective mechanism of low-dose sodium nitrite in oxygen-glucose deprivation model of cerebral ischemic stroke in PC12 cells. EXCLI J. (2019) 18:229-42. doi: 10.17179/excli2018-1947

57. Peng R, Luo M, Tian R, Lu N. Dietary nitrate attenuated endothelial dysfunction and atherosclerosis in apolipoprotein E knockout mice fed a high-fat diet: A critical role for NADPH oxidase. Arch Biochem Biophys. (2020) 689:108453. doi: 10.1016/j.abb.2020.108453

58. Yang Q, Huang Q, Hu Z, Tang X. Potential neuroprotective treatment of stroke: targeting excitotoxicity, oxidative stress, and inflammation. Front Neurosci. (2019) 13:1036. doi: 10.3389/fnins.2019.01036

59. Khambata RS, Ghosh SM, Rathod KS, Thevathasan T, Filomena F, Xiao $\mathrm{Q}$, et al. Antiinflammatory actions of inorganic nitrate stabilize the atherosclerotic plaque. Proc Natl Acad Sci U S A. (2017) 114:E550-e559. doi: $10.1073 /$ pnas.1613063114

60. Jädert C, Petersson J, Massena S, Ahl D, Grapensparr L, Holm L, et al. Decreased leukocyte recruitment by inorganic nitrate and nitrite in microvascular inflammation and NSAID-induced intestinal injury. Free Radic Biol Med. (2012) 52:683-92. doi: 10.1016/j.freeradbiomed.2011.11.018

61. Stokes KY, Dugas TR, Tang Y, Garg H, Guidry E, Bryan NS. Dietary nitrite prevents hypercholesterolemic microvascular inflammation and reverses endothelial dysfunction. Am J Physiol Heart Circ Physiol. (2009) 296:H12811288. doi: 10.1152/ajpheart.01291.2008

62. Raubenheimer K, Bondonno C, Blekkenhorst L, Wagner KH, Peake JM, Neubauer O. Effects of dietary nitrate on inflammation and immune function, and implications for cardiovascular health. Nutr Rev. (2019). 77:584-599. doi: 10.1093/nutrit/nuz025

63. Collmann FM, Pijnenburg R, Hamzei-Taj S, Minassian A, Folz-Donahue $\mathrm{K}$, Kukat $\mathrm{C}$, et al. Individual in vivo profiles of microglia polarization after stroke, represented by the genes iNOS and Ym1. Front Immunol. (2019) 10:1236. doi: 10.3389/fimmu.2019.01236

64. Thiel VE, Audus KL. Nitric oxide and blood-brain barrier integrity. Antioxid Redox Signal. (2001) 3:273-8. doi: 10.1089/152308601300185223

65. Rashid PA, Whitehurst A, Lawson N, Bath PM. Plasma nitric oxide (nitrate/nitrite) levels in acute stroke and their relationship with severity and outcome. J Stroke Cerebrovasc Dis. (2003) 12:82-7. doi: 10.1053/jscd.2003.9

66. Kuzenkov VS. Protective role of nitrate/nitrite reductase system during transient global cerebral ischemia. Bull Exp Biol Med. (2018) 165:31-5. doi: 10.1007/s10517-018-4092-Z

67. Kadan M, Doganci S, Yildirim V, Özgür G, Erol G, Karabacak K, et al. In vitro effect of sodium nitrite on platelet aggregation in human platelet rich plasma-preliminary report. Eur Rev Med Pharmacol Sci. (2015) 19:3935-9.

68. Burnley-Hall N, Abdul F, Androshchuk V, Morris K, Ossei-Gerning N, Anderson $\mathrm{R}$, et al. Dietary nitrate supplementation reduces circulating platelet-derived extracellular vesicles in coronary artery disease patients on clopidogrel therapy: a randomised, double-blind, placebo-controlled study. Thromb Haemost. (2018) 118:112-22. doi: 10.1160/TH17-06-0394

69. Velmurugan S, Gan JM, Rathod KS, Khambata RS, Ghosh SM, Hartley A, et al. Dietary nitrate improves vascular function in patients with hypercholesterolemia: a randomized, double-blind, placebo-controlled study. Am J Clin Nutr. (2016) 103:25-38. doi: 10.3945/ajcn.115. 116244

70. Richardson G, Hicks SL, O’Byrne S, Frost MT, Moore K, Benjamin N, et al. The ingestion of inorganic nitrate increases gastric S-nitrosothiol levels and inhibits platelet function in humans. Nitric Oxide. (2002) 7:24-9. doi: 10.1016/S1089-8603(02)00010-1 
71. Bondonno CP, Blekkenhorst LC, Prince RL, Ivey KL, Lewis JR, Devine A, et al. Association of vegetable nitrate intake with carotid atherosclerosis and ischemic cerebrovascular disease in older women. Stroke. (2017) 48:1724-9. doi: 10.1161/STROKEAHA.117.016844

72. Raubenheimer K, Hickey D, Leveritt M, Fassett R, Ortiz de Zevallos Munoz J, Allen JD, et al. Acute effects of nitrate-rich beetroot juice on blood pressure, hemostasis and vascular inflammation markers in healthy older adults: a randomized, placebo-controlled crossover study. Nutrients. (2017) 9:1270. doi: 10.3390/nu9111270

73. Velmurugan S, Kapil V, Ghosh SM, Davies S, McKnight A, Aboud Z, et al. Antiplatelet effects of dietary nitrate in healthy volunteers: involvement of cGMP and influence of sex. Free Radic Biol Med. (2013) 65:1521-32. doi: 10.1016/j.freeradbiomed.2013.06.031

74. Fan JL, O’Donnell T, Gray CL, Croft K, Noakes AK, Koch H, et al. Dietary nitrate supplementation enhances cerebrovascular CO2 reactivity in a sex-specific manner. J Appl Physiol. (2019) 127:760-9. doi: 10.1152/japplphysiol.01116.2018

75. Hyde ER, Andrade F, Vaksman Z, Parthasarathy K, Jiang H, Parthasarathy $\mathrm{DK}$, et al. Metagenomic analysis of nitrate-reducing bacteria in the oral cavity: implications for nitric oxide homeostasis. PLoS ONE. (2014) 9:e88645. doi: 10.1371/journal.pone.0088645

76. Kapil V, Milsom AB, Okorie M, Maleki-Toyserkani S, Akram F, Rehman F, et al. Inorganic nitrate supplementation lowers blood pressure in humans: role for nitrite-derived NO. Hypertension. (2010) 56:274-81. doi: 10.1161/HYPERTENSIONAHA.110.1 53536

77. Agouni A, Parray AS, Akhtar N, Mir FA, Bourke PJ, Joseph S, et al. There is selective increase in pro-thrombotic circulating extracellular vesicles in acute ischemic stroke and transient ischemic attack: a study of patients from the Middle East and Southeast Asia. Front Neurol. (2019) 10:251. doi: 10.3389/fneur.2019. 00251

78. De Meyer SF, Denorme F, Langhauser F, Geuss E, Fluri F, Kleinschnitz C. Thromboinflammation in stroke brain damage. Stroke. (2016) 47:1165-72. doi: 10.1161/STROKEAHA.115.011238

79. Zhu B, Liu H, Pan Y, Jing J, Li H, Zhao X, et al. Elevated neutrophil and presence of intracranial artery stenosis increase the risk of recurrent stroke. Stroke. (2018) 49:2294-300. doi: 10.1161/STROKEAHA.118.022126

80. Denorme F, Manne BK, Portier I, Eustes AS, Kosaka Y, Kile BT, et al. Platelet necrosis mediates ischemic stroke outcome in mice. Blood. (2020) 135:429-40. doi: 10.1182/blood.2019002124

81. Kapoor S, Opneja A, Nayak L. The role of neutrophils in thrombosis. Thromb Res. (2018) 170:87-96. doi: 10.1016/j.thromres.2018.08.005

82. Sethi S, Dikshit M. Modulation of polymorphonuclear leukocytes function by nitric oxide. Thromb Res. (2000) 100:223-47. doi: 10.1016/S0049-3848(00)00320-0

83. Matsumoto H, Kumon Y, Watanabe H, Ohnishi T, Shudou M, Ii C, et al. Antibodies to CD11b, CD68, and lectin label neutrophils rather than microglia in traumatic and ischemic brain lesions. J Neurosci Res. (2007) 85:994-1009. doi: 10.1002/jnr.21198

84. Rodrigo R, Fernandez-Gajardo R, Gutierrez R, Matamala JM, Carrasco R, Miranda-Merchak A, et al. Oxidative stress and pathophysiology of ischemic stroke: novel therapeutic opportunities. CNS Neurol Disord Drug Targets. (2013) 12:698-714. doi: 10.2174/1871527311312050015

85. Fan JL, O’Donnell T, Lanford J, Croft K, Watson E, Smyth D, et al. Dietary nitrate reduces blood pressure and cerebral artery velocity fluctuations and improves cerebral autoregulation in transient ischemic attack patients. J Appl Physiol. (2020) 129:547-57. doi: 10.1152/japplphysiol.00160.2020

86. Henning SM, Yang J, Shao P, Lee RP, Huang J, Ly A, et al. Health benefit of vegetable/fruit juice-based diet: role of microbiome. Sci Rep. (2017) 7:2167. doi: 10.1038/s41598-017-02200-6

87. Spychala MS, Venna VR, Jandzinski M, Doran SJ, Durgan DJ, Ganesh $\mathrm{BP}$, et al. Age-related changes in the gut microbiota influence systemic inflammation and stroke outcome. Ann Neurol. (2018) 84:23-36. doi: 10.1002/ana.25250

88. Xu K, Gao X, Xia G, Chen M, Zeng N, Wang S, et al. Rapid gut dysbiosis induced by stroke exacerbates brain infarction in turn. Gut. (2021) 70:14861494. doi: 10.1136/gutjnl-2020-323263
89. Pantoni L. Cerebral small vessel disease: from pathogenesis and clinical characteristics to therapeutic challenges. Lancet Neurol. (2010) 9:689-701. doi: 10.1016/S1474-4422(10)70104-6

90. Rensma SP, van Sloten TT, Launer LJ, Stehouwer CDA. Cerebral small vessel disease and risk of incident stroke, dementia and depression, and all-cause mortality: a systematic review and meta-analysis. Neurosci Biobehav Rev. (2018) 90:164-73. doi: 10.1016/j.neubiorev.2018.04.003

91. Wong SM, Jansen JFA, Zhang CE, Hoff EI, Staals J, van Oostenbrugge $\mathrm{RJ}$, et al. Blood-brain barrier impairment and hypoperfusion are linked in cerebral small vessel disease. Neurology. (2019) 92:e1669-77. doi: 10.1212/WNL.0000000000007263

92. Zhang CE, Wong SM, van de Haar HJ, Staals J, Jansen JF, Jeukens $\mathrm{CR}$, et al. Blood-brain barrier leakage is more widespread in patients with cerebral small vessel disease. Neurology. (2017) 88:426-32. doi: 10.1212/WNL.0000000000003556

93. Nezu T, Hosomi N, Aoki S, Kubo S, Araki M, Mukai T, et al. Endothelial dysfunction is associated with the severity of cerebral small vessel disease. Hypertens Res. (2015) 38:291-7. doi: 10.1038/hr.2015.4

94. Wardlaw JM, Smith C, Dichgans M. Small vessel disease: mechanisms and clinical implications. Lancet Neurol. (2019) 18:684-96. doi: 10.1016/S1474-4422(19)30079-1

95. van Sloten TT, Protogerou AD, Henry RM, Schram MT, Launer LJ, Stehouwer CD. Association between arterial stiffness, cerebral small vessel disease and cognitive impairment: a systematic review and meta-analysis. Neurosci Biobehav Rev. (2015) 53:121-30. doi: 10.1016/j.neubiorev.2015.03.011

96. Presley TD, Morgan AR, Bechtold E, Clodfelter W, Dove RW, Jennings JM, et al. Acute effect of a high nitrate diet on brain perfusion in older adults. Nitric Oxide. (2011) 24:34-42. doi: 10.1016/j.niox.2010.10.002

97. Hassan A, Gormley K, O'Sullivan M, Knight J, Sham P, Vallance P, et al. Endothelial nitric oxide gene haplotypes and risk of cerebral small-vessel disease. Stroke. (2004) 35:654-9. doi: 10.1161/01.STR.0000117238.75736.53

98. Rolfs A, Böttcher T, Zschiesche M, Morris P, Winchester B, Bauer P, et al. Prevalence of Fabry disease in patients with cryptogenic stroke: a prospective study. Lancet. (2005) 366:1794-6. doi: 10.1016/S0140-6736(05)67635-0

99. Feigin VL, Grant N, Kelly C, O JC, Tahiya A, G PP, et al. Global, Regional, and Country-Specific Lifetime Risks of Stroke, 1990 and 2016. N Engl J Med. (2018) 379:2429-37. doi: 10.1056/NEJMoa1804492

100. Moore DF, Scott LT, Gladwin MT, Altarescu G, Kaneski C, Suzuki K, et al. Regional cerebral hyperperfusion and nitric oxide pathway dysregulation in Fabry disease: reversal by enzyme replacement therapy. Circulation. (2001) 104:1506-12. doi: 10.1161/hc3801.096352

101. O’Brien JT, Thomas A. Vascular dementia. Lancet. (2015) 386:1698-706. doi: 10.1016/S0140-6736(15)00463-8

102. Corzo L, Zas R, Rodríguez S, Fernández-Novoa L, Cacabelos R. Decreased levels of serum nitric oxide in different forms of dementia. Neurosci Lett. (2007) 420:263-7. doi: 10.1016/j.neulet.2007.05.008

103. Sharma B, Singh N. Pharmacological inhibition of inducible nitric oxide synthase (iNOS) and nicotinamide adenine dinucleotide phosphate (NADPH) oxidase, convalesce behavior and biochemistry of hypertension induced vascular dementia in rats. Pharmacol Biochem Behav. (2013) 103:821-30. doi: 10.1016/j.pbb.2012.11.011

104. Incalza MA, D’Oria R, Natalicchio A, Perrini S, Laviola L, Giorgino F. Oxidative stress and reactive oxygen species in endothelial dysfunction associated with cardiovascular and metabolic diseases. Vascul Pharmacol. (2018) 100:1-19. doi: 10.1016/j.vph.2017. 05.005

105. Zhu HY, Hong FF, Yang SL. The roles of nitric oxide synthase/nitric oxide pathway in the pathology of vascular dementia and related therapeutic approaches. Int J Mol Sci. (2021) 22:4540. doi: 10.3390/ijms22094540

106. Yoshikawa T, Murase K, Oku N, Imaizumi M, Takasawa M, Rishu P, et al. Heterogeneity of cerebral blood flow in Alzheimer disease and vascular dementia. AJNR Am J Neuroradiol. (2003) 24:1341-7.

107. Wightman EL, Haskell-Ramsay CF, Thompson KG, Blackwell JR, Winyard PG, Forster J, et al. Dietary nitrate modulates cerebral blood flow parameters and cognitive performance in humans: a double-blind, placebocontrolled, crossover investigation. Physiol Behav. (2015) 149:149-58. doi: 10.1016/j.physbeh.2015.05.035 
108. Sindelar JJ, Milkowski AL. Human safety controversies surrounding nitrate and nitrite in the diet. Nitric Oxide. (2012) 26:259-66. doi: 10.1016/j.niox.2012.03.011

109. Habermeyer M, Roth A, Guth S, Diel P, Engel KH, Epe B, et al. Nitrate and nitrite in the diet: how to assess their benefit and risk for human health. $\mathrm{Mol}$ Nutr Food Res. (2015) 59:106-28. doi: 10.1002/mnfr.201400286

110. Hord NG, Tang Y, Bryan NS. Food sources of nitrates and nitrites: the physiologic context for potential health benefits. Am J Clin Nutr. (2009) 90:1-10. doi: 10.3945/ajcn.2008.27131

111. Bedale W, Sindelar JJ, Milkowski AL. Dietary nitrate and nitrite: Benefits, risks, and evolving perceptions. Meat Sci. (2016) 120:85-92. doi: 10.1016/j.meatsci.2016.03.009

112. Bryan NS, Alexander DD, Coughlin JR, Milkowski AL, Boffetta P. Ingested nitrate and nitrite and stomach cancer risk: an updated review. Food Chem Toxicol. (2012) 50:3646-65. doi: 10.1016/j.fct.2012.07.062

113. Burleigh M, Liddle L, Muggeridge DJ, Monaghan C, Sculthorpe N, Butcher $\mathrm{J}$, et al. Dietary nitrate supplementation alters the oral microbiome but does not improve the vascular responses to an acute nitrate dose. Nitric Oxide. (2019) 89:54-63. doi: 10.1016/j.niox.2019.04.010

114. Rogers SC, Zhang X, Azhar G, Luo S, Wei JY. Exposure to high or low glucose levels accelerates the appearance of markers of endothelial cell senescence and induces dysregulation of nitric oxide synthase. J Gerontol A Biol Sci Med Sci. (2013) 68:1469-81. doi: 10.1093/gerona/glt033

115. Jansson EA, Huang L, Malkey R, Govoni M, Nihlén C, Olsson A, et al. A mammalian functional nitrate reductase that regulates nitrite and nitric oxide homeostasis. Nat Chem Biol. (2008) 4:411-7. doi: 10.1038/nchem bio. 92

116. Koch CD, Gladwin MT, Freeman BA, Lundberg JO, Weitzberg E, Morris A. Enterosalivary nitrate metabolism and the microbiome: Intersection of microbial metabolism, nitric oxide and diet in cardiac and pulmonary vascular health. Free Radic Biol Med. (2017) 105:48-67. doi: 10.1016/j.freeradbiomed.2016. 12.015

117. English C, MacDonald-Wicks L, Patterson A, Attia J, Hankey GJ. The role of diet in secondary stroke prevention. Lancet Neurol. (2021) 20:150-60. doi: 10.1016/S1474-4422(20)30433-6

118. Kim F, Maynard C, Dezfulian C, Sayre M, Kudenchuk P, Rea T, et al. Effect of out-of-hospital sodium nitrite on survival to hospital admission after cardiac arrest: a randomized clinical trial. JAMA. (2021) 325:138-45. doi: 10.1001/jama.2020.24326

119. Gago B, Lundberg JO, Barbosa RM, Laranjinha J. Red wine-dependent reduction of nitrite to nitric oxide in the stomach. Free Radic Biol Med. (2007) 43:1233-42. doi: 10.1016/j.freeradbiomed.2007.06.007

120. Carlström M, Lundberg JO, Weitzberg E. Mechanisms underlying blood pressure reduction by dietary inorganic nitrate. Acta Physiol (Oxf). (2018) 224:e13080. doi: 10.1111/apha.13080

121. Montenegro MF, Sundqvist ML, Larsen FJ, Zhuge Z, Carlström M Weitzberg E, et al. Blood pressure-lowering effect of orally ingested nitrite is abolished by a proton pump inhibitor. Hypertension. (2017) 69:23-31. doi: 10.1161/HYPERTENSIONAHA.116.08081

122. Bryan NS, Tribble G, Angelov N. Oral microbiome and nitric oxide: the missing link in the management of blood pressure. Curr Hypertens Rep. (2017) 19:33. doi: 10.1007/s11906-0170725-2

Conflict of Interest: The authors declare that the research was conducted in the absence of any commercial or financial relationships that could be construed as a potential conflict of interest.

The reviewer YW declared a shared affiliation with the authors to the handling editor at time of review.

Publisher's Note: All claims expressed in this article are solely those of the authors and do not necessarily represent those of their affiliated organizations, or those of the publisher, the editors and the reviewers. Any product that may be evaluated in this article, or claim that may be made by its manufacturer, is not guaranteed or endorsed by the publisher.

Copyright (c) 2022 Wang, Chen, Zhou, Wang, Wang and Wang. This is an openaccess article distributed under the terms of the Creative Commons Attribution License (CC BY). The use, distribution or reproduction in other forums is permitted, provided the original author(s) and the copyright owner(s) are credited and that the original publication in this journal is cited, in accordance with accepted academic practice. No use, distribution or reproduction is permitted which does not comply with these terms. 